\title{
De lo que aconteció cuando Martín Sarmiento se subió a la zebra del moro Muzaraque y encontró a Cervantes en el camino de Alcalá
}

\author{
José Santos Puerto* \\ Elena Santos Vega*
}

\section{LAS CONTRADICTORIAS IDEAS DE SARMIENTO SOBRE}

\section{LA PATRIA DE LOS ESCRITORES}

El benedictino Martín Sarmiento, personaje esencial para comprender lo que fue y lo que no pudo ser la Ilustración española ${ }^{1}$, es también figura clave para la historiografía literaria de nuestro siglo XVIII, pues a él le debemos algunos de los primeros apuntes e intuiciones sobre la importancia de la poesía medieval española, de la obra de Berceo, del Poema de Mío Cid y de las Cantigas de Alfonso $\mathrm{X}^{2}$.

Sarmiento sembró sus escritos de abundantes noticias personales como estrategia para introducirse en el texto e interesar a los futuros lectores de sus manuscritos, que no estaban pensados para ser publicados. Ese proceder, que hoy nos permite reconstruir parte de su vida, lo tomó de Cervantes y principalmente de su admirado Caramuel.

De Cervantes tomó también la sorprendente regla de no revelar el lugar de su nacimiento y bautismo. Y decimos sorprendente porque creía que, para evitar inútiles porfías y pérdidas de tiempo sobre si un autor fue de aquí o de allá, era necesario dictar alguna ley «obligando a cualquier autor que haya de dar a luz e imprimir un libro, para que (...) noticie al público quién es, de dón-

* Universidad de La Laguna.

1. Pensado Tomé, José Luis, Fray Martín Sarmiento, testigo de su siglo, Salamanca: Universidad de Salamanca, 1972. Santos Puerto, José, Martín Sarmiento. Ilustración, educación y utopía en la España del siglo XVIII, A Coruña: Fundación Barrié de la Maza, 2002.

2. Sarmiento, Martín, Memorias para la historia de la poesía y poetas españoles, Madrid: Ibarra, 1775. El texto había sido redactado entre 1741 y 1745 a petición del cardenal Valentí Gonzaga. 
de, qué estado y profesión tiene, qué empleos posee, qué edad tiene, cuándo nació y en qué parroquia está bautizado, qué padres tiene o ha tenido» ${ }^{3}$.

Sarmiento no cumplió con las obligaciones que pretendía exigir a los demás, originando una polémica sobre el lugar de su propio nacimiento que dura hasta nuestros días ${ }^{4}$. Lo más curioso es que él fue quien halló la partida de bautismo de Caramuel en San Martín de Madrid $^{5}$ y que fue él quien sentó las bases para encontrar la partida de bautismo de Cervantes en Alcalá de Henares, como aquí vamos a recordar con detalle.

\section{Cervantes, Martín SARMiento Y SU ESCRITO SOBRE LA ZEBRA}

Antes de 1752 se ignoraba a ciencia cierta el lugar de nacimiento de Cervantes y varias poblaciones se disputaban ese honor. Algunos le tenían por natural de Madrid, siguiendo a Gregorio Mayans, que así lo había asentado en 1737 al escribir la Vida de Miguel de Cervantes Saavedra, para encabezar la lujosa edición inglesa del Quijote patrocinada por Lord Carteret. Allí decía Mayans: «después de muerto es prohijado a porfía de muchas patrias. Esquivias dice ser suyo. Sevilla le niega esta gloria, y la quiere para sí. Lucena tiene la misma pretensión. Cada una alega su derecho; y ninguna le tiene. (...) Entretanto tengo por cierto que la patria de Cervantes fue Madrid, pues él mismo en el Viaje del Parnaso, despidiéndose de esta grande villa, le dice así» ${ }^{6}$.

No todo el mundo asentía a esa propuesta de Gregorio Mayans. Por eso Sarmiento se quejaba en 1743 de que no se supiera el lugar exacto del nacimiento de Cervantes: «¿Qué cosa más lastimosa — decía en sus Reflexiones

3. Sarmiento, Martín, Reflexiones Literarias para una Biblioteca Real, Edición de José Santos, Santiago: Consello da Cultura Galega, 2002, § 415. Ideas parecidas formula años más tarde: «Tiempo han tenido los autores de haber escarmentado viendo el tiempo que inútilmente gastan los críticos en averiguar la patria y edad de algunos autores antiguos cuando es ya inaveriguable. Si se entablase la práctica de que cada escritor pusiese al principio y al fin de la materia de su obra, o en otro lugar oportuno, la nota de su edad y de su patria, se evitaría, en lo adelante, tanto inútil escrito sobre la patria y edad de este o del otro autor» (Sarmiento, Martín, Noticia de la verdadera patria (Alcalá) de El Miguel de Cervantes, Edición de José Luis Pensado, Santiago: Xunta de Galicia, 1987, § 7).

4. Santos, José, «Martín Sarmiento, natural de San Juan de Cerdedo», Sarmiento. Anuario Galego de Historia da Educación, n. ${ }^{\circ}$ 12, 2008, pp. 9-21.

5. Sarmiento, Martín, Noticia de la verdadera patria de Miguel de Cervantes, citada, § 10.

6. Mayans, Gregorio, Vida de Miguel de Cervantes Saavedra, Briga-Real, 1737, pp. 1-3. Mayans imprimió esa Vida en castellano por encargo de Lord Carteret, que la mandó traducir al inglés para encabezar la edición inglesa del Quijote, que vio la luz al año siguiente, The Life of Michael de Cervantes Saavedra, London: J. \& R. Tonson, 1738. Unos años después apareció en Madrid, con título Vida de Miguel de Cervantes Saavedra natural de Madrid, Madrid: Alonso i Padilla, 1750. Desde entonces el texto de Mayans ha sido reeditado en numerosas ocasiones. Puede consultarse, junto con otros textos del siglo XVIII, en la edición de Antonio Rey Hazas y Juan Ramón Muñoz Sánchez, El nacimiento del cervantismo. Cervantes y el Quijote en el siglo XVIII, Madrid: Verbum, 2006. 
Literarias - que no saber al presente la patria de Cervantes, habiéndose hecho tan famoso por su Historia de Don Quijote?» ${ }^{7}$.

Naturalmente, no sabía entonces que gracias a él se llegaría a redescubrir que la patria de Cervantes era Alcalá de Henares, y no Madrid. Eso ocurrió en los primeros meses del año 1752, cuando el benedictino asentó esa importante novedad para la historia de la literatura en su escrito Sobre la Zebra, como ya en su día señaló Vicente de los Ríos:

El primero que escribió con solidez sobre la patria de Cervantes fue el erudito P.M. Sarmiento (...) en su disertación sobre la cebra, que escribió en Madrid el año de 1752: advierto de paso que en llamar Cervantes a la capital la gran Compluto, miraría acaso a señalar su patria con aquel elogio de grande, siendo cierto que según el padre Haedo era Miguel de Cervantes un hidalgo principal de Alcalá ${ }^{8}$.

Conviene, por tanto, conocer algo más de ese escrito Sobre la Zebra de Martín Sarmiento, que sorprendentemente todavía no ha sido publicado. El trabajo, fechado en Madrid a 24 de junio de 1752, fue entregado a su paisano de Pontevedra el conde de Maceda, personaje con gran influencia en el Madrid de los primeros tiempos del reinado de Fernando VI, ya que en julio de 1746 el nuevo rey lo había nombrado gobernador de la capital, con mando militar y político, asumiendo también las facultades y prerrogativas anejas al corregidor de Madrid.

Ignoramos por qué el conde se interesó por la cebra en 1752. Y tampoco sabemos por qué recurría a Sarmiento, que hasta entonces no había escrito ni publicado nada relevante relacionado con los animales. Nos inclinamos a pensar que la iniciativa no partió de Maceda sino del propio Sarmiento. Y eso se debió a que, como consecuencia de sus estudios históricos, etimológicos y toponímicos, el benedictino llegó al convencimiento de que la cebra era animal existente en la España medieval, e intentó usar la influencia que Maceda tenía en los círculos reales para convencer al monarca de la necesidad de mandar traer a Madrid algunos ejemplares de cebras africanas para avecindarlas en los montes españoles.

Martín Sarmiento alude a varios fueros, documentos y textos de autores castellanos antiguos para mostrar que zebra, zebro, cebra, cebro, y sus derivados, son nombres castellanos utilizados para denominar a unos animales que se criaban y cazaban en la España medieval, en donde se apreciaba mucho su piel. Como el propio monje explica, las huellas y la presencia de aquellos animales en España pervive en la toponomástica y en los nombres de lugares y montes en donde en otro tiempo abundaban y se cazaban.

7. Sarmiento, Martín, Reflexiones Literarias para una Biblioteca Real, citada, § 417.

8. Ríos, Vicente de los, «Vida de Miguel de Cervantes y análisis del Quijote», en El Ingenioso Hidalgo don Quixote de la Mancha, compuesto por Miguel de Cervantes Saavedra. Nueva edición corregida por la Real Academia Española, Madrid: Joaquín Ibarra, 1780, parte primera, tomo I, p. CLXVII. 
Citando y cotejando un pasaje de Sampiro, que el arzobispo D. Rodrigo había insertado en su Historia Latina, Sarmiento establece que el zebro es el onagro, o asno salvaje de griegos y latinos, frecuentemente citado y descrito por los autores de la antigüedad. El benedictino gallego asume que las descripciones del onagro se corresponden con las descripciones medievales del zebro y que el zebro y el onagro son muy parecidos a las cebras que subsisten en África. Y entiende que debe tratarse del mismo animal. Cree, y propone como verosímil, que las palabras zebra, zebro, y sus derivados, tienen su procedencia y raíz en el hebreo y que fueron introducidas en España por alguno de los muchos pueblos orientales que la invadieron y poblaron, subsistiendo con la denominación greco-latina onagro, que poco a poco fue cayendo en desuso en el castellano.

En su larga digresión el benedictino da noticias relacionadas con otros animales menos conocidos y explicaciones de algunos vocablos poco usuales, dejando apuntado que los murcibios de los que había hablado Gratio Falisco pudieran ser zebras y que la voz murcibio podría derivar de mulo y cebro, de acuerdo con esta evolución: mulo-cebro, murcebro, murcebo, murcibo, murcibio ${ }^{9}$. También deja apuntada la posibilidad de que los equus feri, equiferi, que Varrón suponía originarios del centro de España, podían ser en realidad enzebras $^{10}$. Finaliza reiterando que la zebra, el más hermoso de los cuadrúpedos en palabras de Jobo Ludolfo, nacía, se criaba y se cazaba antaño en España, por lo que proponía su restitución, trayendo algunos ejemplares de África. Y para que no se considerase una propuesta disparatada, recordaba que en otro tiempo los portugueses habían remitido desde África cuatro zebras a Lisboa, que se habían domado y eran utilizadas en la carroza del rey de Portugal.

El benedictino conocía que en la mayor parte de las descripciones antiguas y medievales el onagro sólo aparece con rayas en las patas y no con rayas blancas y negras por todo el cuerpo, como ocurría con las cebras africanas. Era por eso consciente de que las opiniones podían ser encontradas, y que algunos señalarían que las cebras existentes antiguamente en España y las actuales de África «acaso no será un mismo animal, sino en el nombre». A lo que él puntualizaba: «aún concediendo que no son un mismo animal, a lo menos se debían domar y traer, o para tentar si con la experiencia, son las antiguas cebras españolas; o para curiosidad y ostentación de la magnificencia real». Argumento que le servía para generalizar la idea de «restituir a España todas las especies de animales, aves, y vegetables, que se sabe han sido naturales del país, y se han perdido, sino también, mandar que a España se trasplanten todas las especies peregrinas, que puedan producir y fructificar en ella. Vegetables para maderas, frutos, y medicinas. Aves para carnes, pluma y canto. Y animales inocentes, para lanas, pelo, carnes y pieles» ${ }^{11}$.

9. Sarmiento, Martín, Zebra, § 133. Como se ha señalado antes, el texto no ha sido publicado, pero existe una transcripción realizada por Elena Santos y José Santos, alojada en la web del Museo de la Educación de la Universidad de La Laguna. Nuestras referencias están tomadas de ese documento, 〈http://webpages.ull.es/users/medull/pedagogos/SARMIENTO/Zebra.pdf〉

10. Ibídem, § 137.

11. Ibídem, § 165 . 


\section{¿Cuándo y cómo descubrió Sarmiento que Alcalá ERA LA PATRIA DE CERVANTES?}

Es en el contexto de búsqueda de textos y argumentos probatorios de que la cebra era animal frecuente en los montes de la España medieval en el que se produce el hallazgo de que Alcalá de Henares era la patria de Cervantes. La noticia había sido recogida en la Topographia e Historia General de Argel, publicada en 1612 por Diego de Haedo ${ }^{12}$. Pero la referencia se olvidó, o no se le prestó excesiva atención ya que ni en aquellas fechas Cervantes había adquirido la fama que luego alcanzó ni el libro de Haedo tuvo mucha venta. En ese sentido ya señaló Navarrete que Haedo y Méndez de Silva, autores que en el siglo XVII habían dejado constancia en su obra de que la patria de Cervantes era Alcalá, «ni al parecer fueron leídos de muchos, ni fijaron la atención de los que en todo el siglo XVII y en la mitad del siguiente se propusieron hablar de nuestro escritor» ${ }^{13}$.

Sarmiento explicó en varias ocasiones en qué fechas conoció el texto de Haedo, vinculando ese hecho con la redacción de su trabajo Sobre la Zebra: «La primavera de 752, cuando tropecé con el texto del P. Haedo, en la Historia de Argel, tenía yo entre manos apurar toda la historia del animal zebra (...) En ese papel apunté la noticia de haber tropezado con la patria de Cervantes» ${ }^{14}$. Faltaban varias semanas para que el benedictino finalizase aquel trabajo, pues cuando leyó el texto de Haedo corría el mes de abril, como señala en su catálogo de libros, en los apartados correspondientes a Haedo y a Cervantes ${ }^{15}$.

El monje benedictino comentó la noticia con su amigo Manuel de Mena, y le encargó difundirla «en la real biblioteca y en otros congresos de literatos,

12. Hoy se discute que Haedo fuese el autor de la Topographia e Historia General de Argel. Se atribuye al doctor Antonio de Sosa, amigo de Cervantes (Sosa, Antonio de. Diálogo de los mártires de Argel, Edición de Emilio Sola y José M. ${ }^{a}$ Parreño, Madrid: Hiperion, 1990), y acaso con menos fortuna, también al propio Cervantes (Eisenberg, Daniel, «Cervantes, autor de la Topografia e Historia general de Argel publicada por Diego de Haedo», Cervantes: Bulletin of the Cervantes Society of America, 16, 1996, pp. 32-53).

13. Fernández Navarrete, Martín, Vida de Miguel de Cervantes Saavedra. Escrita e ilustrada con varias noticias y documentos inéditos, Madrid: Imprenta Real, 1819, p. 202.

14. Sarmiento, Martín, Noticia de la verdadera patria de Miguel de Cervantes, citada, § 116. La noticia aparece, efectivamente, en el trabajo sobre la Zebra, § 51: «y advierto, de paso, que en llamar Cervantes a la capital, la Gran Compluto, miraría acaso a señalar su patria con aquel elogio de grande; siendo cierto que, según la Historia de Argel del P. Haedo, era Miguel Cervantes un hidalgo principal de Alcalá de Henares».

15. Sarmiento, Martín, Índice individual de los 6500 volúmenes de libros, y algunos más, que este año de 767 poseo ad usum, Real Academia de la Historia, Ms. 9/1829. En la reseña de Haedo anotó: «Historia General de Argel, selecto y raro. En el folio 185 está la noticia de que era natural de Alcalá Miguel Cervantes. La cual advertí yo el primero por abril de 1752, y después D. Agustín Montiano sacó la fe de bautismo el año de 1547. Y la pone citándome a mí en el Discurso II sobre las tragedias españolas, pág. 9». Y en la reseña de las obras de Cervantes señala algo parecido: «Leyendo yo por el abril de 752 la Historia de Argel de fr. Diego de Haedo, tropecé con una columna de la página 185, que toda habla de este Miguel de Cervantes, cautivo en Argel, y de él se escribe que era de Alcalá de Henares. Hice público el hallazgo, para que algún curioso registrase los libros de bautizados». 
para que, si alguno quisiese tratar ese punto, buscase en Alcalá la fe de bautismo de Cervantes» ${ }^{16}$. Y efectivamente, el librero Mena esparció con rapidez la referencia, que también conoció Gregorio Mayans en Valencia, transmitida por Martínez Pingarrón, que le comunicaba su disposición para mandar pedir una partida de bautismo por mediación de un amigo que tenía en Alcalá ${ }^{17}$.

La correspondencia del bibliotecario Martínez Pingarrón con Gregorio Mayans nos confirma que la casa del librero Manuel de Mena se convirtió en el principal foco de difusión de la noticia, como quería Sarmiento al comunicársela, y nos aporta alguna luz sobre la cronología de los sucesos que llevaron a encontrar la fe de bautismo de Cervantes.

\section{CARRERA PARA ENCONTRAR LA PARTIDA DE BAUTISMO Y RETRASO DE MARTÍNEZ PINGARRÓN}

En carta de 9 de junio de 1752 Martínez Pingarrón señalaba a Mayans: «estando en casa de Mena días pasados, encontré con un amigo mío que estaba apuntando lo que va en el papelito adjunto, y yo lo anoté para enviarlo a Vmd» ${ }^{18}$. El hecho había ocurrido algunos días antes, pero Martínez Pingarrón tardó en avisar a Mayans porque, como le explicaba al inicio de la misma carta citada, entre el 18 de mayo y el 6 de junio tuvo que permanecer en El Escorial ayudando a Miguel Casiri a clasificar los códices arábigos. Sorprende que Antonio Mestre, que como es natural utilizó la correspondencia citada aquí en el prólogo de la Vida de Miguel de Cervantes de Gregorio Mayans ${ }^{19}$, no hubiese hecho referencia a esta estancia de Martínez Pingarrón en El Escorial, con la indudable importancia que tiene para la cronología de la búsqueda de la partida de bautismo de Cervantes.

De vuelta a Madrid, el bibliotecario Pingarrón escribió a su amigo adjuntándole el papelito señalado, e indicándole que hiciese sus combinaciones por si creía oportuno buscar en Alcalá la partida de bautismo. Por demás está decir que en el papel adjunto Pingarrón enviaba a Mayans la noticia que relaciona a Cervantes con Alcalá, con indicación del capítulo y la página del libro de Diego de Haedo en donde podía consultarla.

16. Sarmiento, Martín, Noticia de la verdadera patria..., citada, § 43. Y añadía: «Creo que algunos hicieron la diligencia. El que más se esmeró ha sido D. Agustín de Montiano y Luyando, secretario de SM, de la cámara de gracia y justicia, y director perpetuo de la Real Academia de la Historia».

17. Mayans, Gregorio, Epistolario. VII, Mayans y Martínez Pingarrón, 1, transcripción, notas y estudio preliminar de Antonio Mestre, Valencia: Ayuntamiento de Oliva, 1987, p. 397.

18. Ibídem, p. 396. La carta tiene fecha de 9 de junio de 1752. La anterior carta remitida por Martínez Pingarrón a Mayans es del 6 de mayo, y nada se comenta allí de Cervantes. De modo que la noticia sobre Cervantes le llegó a Martínez Pingarrón, vía casa de Mena, entre el 6 y el 18 de mayo.

19. Mestre, Antonio, «Prólogo» de Gregorio Mayans, Vida de Miguel de Cervantes Saavedra, Madrid: Espasa-Calpe, 1972, pp. LXXVI-XCII. 
La siguiente carta de Martínez Pingarrón está fechada el 24 de junio. Por el contexto se deduce que Mayans le había señalado que no tenía la Topographia e Historia de Argel y que le pedía buscar la fe de bautismo. El bibliotecario contesta que hará la diligencia para buscar la partida y hace un breve elogio del libro de Haedo: «aunque D. Nicolás Antonio no le elogie, en lo que yo he visto de él no me ha parecido mal; trae los hechos, nombra los sujetos y no es libro obvio. No obstante no le enviaré hasta que Vmd. me lo diga» ${ }^{20}$.

Ha pasado algo más de un mes, cuando el 29 de julio Pingarrón le comunica grandes novedades a Gregorio Mayans: «Mi dueño y amigo. Tenemos a Miguel de Cervantes hijo de Alcalá de Henares, como verá por la copia de la certificación del cura de Sta. María de aquella ciudad, con inserción de la partida de bautismo, cuyo original he puesto en esta real biblioteca, con la carta del abad, D. Santiago Gómez Falcón» ${ }^{21}$.

En la siguiente carta, fechada en 12 de agosto, Pingarrón señala que no ha sentado bien en los círculos de Montiano que él hubiese divulgado la fe de bautismo, «porque con la noticia que él tuvo (como yo) de lo que había hallado el P. Sarmiento en Haedo, hizo las diligencias para averiguarlo; quieren decir que antes que yo, pero no lo creo. Últimamente me dicen está en ánimo de publicar esta noticia en una obra suya que quiere imprimir» ${ }^{22}$. En febrero de 1753 Martínez Pingarrón ya sabe que se va a publicar la partida y teme lo peor de Montiano «cuya maña o de algún cliente suyo pudo hacer que le diesen una certificación con fecha anterior a la mía» ${ }^{23}$. Y efectivamente, al poco tiempo Agustín Montiano publicó la fe de bautismo de Cervantes en Alcalá, afirmando que la noticia encontrada por fr. Martín Sarmiento en la obra de Haedo le había puesto en el camino ${ }^{24}$.

La disputa sobre quién llegó antes a la fe de bautismo, si Montiano a través de Baza, contador de rentas decimales de Alcalá, o si Martínez Pingarrón a través de su amigo Santiago Gómez Falcón, acaso tenía pronta respuesta entre los bibliotecarios y empleados de la biblioteca real, ya que, según decía Martínez Pingarrón a Mayans, allí se había hecho pública la partida aportada por él y no la de Montiano. Pero fuera de la biblioteca era más difícil la discusión, desde el momento en que, como Pingarrón temía, la certificación aportada por Montiano estaba firmada por el mismo Sebastián García Calvo y tenía fecha de 19 de junio de 1752, es decir un mes antes que la aportada por el bibliotecario Pingarrón.

20. Mayans, Gregorio, Epistolario. VII, p. 398

21. Ibídem, p. 402. La partida de bautismo de Miguel de Cervantes conseguida por Martínez Pingarrón, certificada por Sebastián García Calvo y fecha en Alcalá de Henares el 18 de julio de 1752, fue publicada años después por Pellicer, Juan Antonio, Ensayo de una biblioteca de traductores españoles, Madrid: Antonio Sancha, 1778, pp. 189-190.

22. Mayans, Gregorio, Epistolario. VII, p. 403.

23. Ibídem, p. 417.

24. Montiano, Agustín, Discurso II sobre las Tragedias Españolas, Madrid: Imprenta del Mercurio, 1753, pp. 9-10. En nota al pie se pone la partida literal, señalando que fue dada el 19 de junio de 1752 por el Dr. Sebastián García Calvo. 
A favor de Martínez Pingarrón está su convencimiento, reiterado en cartas escritas a Mayans, de que Montiano había usado de sus malas artes e influencias para conseguir que el párroco García Calvo le entregase un certificado amañado en las fechas. Eso equivale a decir que Pingarrón y quienes le siguieron trataban de falsarios a Montiano y al cura.

A favor de Martínez Pingarrón se mostró Pellicer i Saforcada, publicando una carta de Gómez Falcón, el amigo de Pingarrón en Alcalá que hizo las gestiones para conseguir la partida de bautismo. En esa carta, fechada en agosto de 1752, dice Gómez Falcón: «encuentro que avisado alguno de la diligencia que hacía yo para la fe de bautismo, o estimulado de alguno de Madrid, sacó la misma partida de bautismo que yo envié, con algunos días de antelación, y la envió el señor Baeza, contador mayor de rentas decimales» ${ }^{25}$. Puede dar lugar a equívocos la expresión «con algunos días de antelación». ¿Se refiere Gómez Falcón a que alguien sacó la partida con algunos días de antelación? ¿O que él envió la partida con algunos días de antelación?

Si hubiera querido decir lo primero, tendríamos entonces que concluir que Martínez Pingarrón no había tomado la delantera para conseguir la partida de bautismo, por más que él la hubiese hecho pública en la real biblioteca. Lo más favorable para Martínez Pingarrón sería que Gómez Falcón hubiese querido decir que él había enviado la partida con algunos días de antelación, y de ahí podríamos inferir que también la había conseguido antes que sus competidores. Lo que el contenido de la carta de Gómez Falcón no nos permite de ningún modo afirmar es que se amañó la fecha de la certificación con destino a Montiano, como sí pudieron inferir Pingarrón y Mayans ${ }^{26}$, que a lo mejor eran conocedores de otros hechos y circunstancias que les permitían pensar en una componenda de Montiano.

Lo que sorprende es la interpretación sesgada que Pellicer hacía del documento que él mismo aportaba, afirmando que, de acuerdo con la carta de Gómez Falcón, alguien «sacó la misma partida de bautismo de Cervantes poco después que se le dio a él la certificación mencionada y que en obsequio del interesado se usó la cortesía de poner la fecha con algunos días de antelación» ${ }^{27}$. Esas afirmaciones no aparecen en la carta de Falcón. Y como no queremos pensar que fuese una burda invención de Pellicer, nos atrevemos a conjeturar que éste se limitó a repetir lo que desde 1753 era lugar común en los círculos de Pingarrón y de Mayans, sin atender a la lectura de la misiva de Gómez Falcón.

25. Pellicer, Juan A., Ensayo de una biblioteca de traductores..., citado, p. 190.

26. Ya hemos visto que esa idea había sido planteada por Martínez Pingarrón a Mayans en cartas de agosto de 1752 y de febrero de 1753. Mayans repitió argumentos parecidos a finales de abril de 1761, en carta dirigida a Diego de Morales: «como yo tenía ya averiguado poco más o menos el tiempo de su nacimiento, me hizo sacar la fe de su bautismo mi amigo Manuel Martínez Pingarrón. Diligencia que se practicó antes que se refiriese como gran triunfo de mi ignorancia tal hallazgo, haciendo retroceder el tiempo de su licencia, como si la victoria fuera de lustre, y el libro de Haedo no estuviera impreso desde el año 1612» (Mayans, Gregorio, Epistolario, XV. Mayans y los altos cargos. 2, Edición y estudio de Antonio Mestre y Pablo Pérez, Ayuntamiento de Oliva, 1997, p. 323).

27. Pellicer, Juan A., Ensayo de una biblioteca..., citada, p. 144. 
Hoy podemos decir que los planteamientos de Pellicer, basados en una mala lectura de la carta de Gómez Falcón, no sirven para avalar la idea de que Pingarrón se anticipó a Montiano en la carrera por conseguir la partida de bautismo de Cervantes. De modo que a favor de Pingarrón sólo contamos con sus apreciaciones personales, contradictorias con otros hechos que avalan la tesis contraria, es decir que fue Montiano quien se adelantó.

$\mathrm{Y}$ es que en contra de Martínez Pingarrón hay circunstancias que quizás no se han valorado bien. No nos referimos sólo a las fechas de las certificaciones, sino también a la propia correspondencia de Pingarrón con Mayans, que nos convence de que cuando el bibliotecario inició la carrera hacia Alcalá podía llevar varias semanas de desventaja. El retraso de Pingarrón se debió a su estancia en El Escorial con Miguel Casiri entre el 18 de mayo y el 6 de junio, a lo que debe añadirse el tiempo que media entre la comunicación a Mayans y la respuesta de éste, por lo que la decisión de iniciar la búsqueda de la partida en Alcalá no la tomó Pingarrón hasta el 24 de junio, que fue cuando escribió a Mayans: «Pediré a Alcalá se haga la diligencia de la partida de bautismo de Miguel de Cervantes».

Desconcierta advertir que el yerro de Juan Antonio Pellicer, en cuanto a la carta de Gómez Falcón, fuese asumido de forma poco crítica por algunos estudiosos de Cervantes y que las apreciaciones subjetivas de Pellicer sirvieran para afirmar - como aún lo hacía Antonio Mestre en 1972- que Martínez Pingarrón fue el primero en culminar la carrera hacia Alcalá. Ocultando $-\mathrm{u}$ olvidando - que cuando Martínez Pingarrón inició la carrera habían transcurrido ya dos meses desde que Martín Sarmiento diera con el texto de Haedo, y que con aquel retraso era más que probable que otros ganasen la partida, como pudo hacer Agustín Montiano, o quien en su nombre consiguió la fe de bautismo.

\section{Por QuÉ Y CÓMO LLEGó SARMIENTO A LEER LA NOTICIA DEL TEXTO DE HAEDO}

Nadie discutió ni puso en duda en aquellos años que la ruta para encontrar la partida de Cervantes en Alcalá de Henares la había marcado Martín Sarmiento al dar cuenta de la novedosa noticia contenida en la Topographia e Historia General de Argel. Sobre ese particular son inequívocas las declaraciones de quienes se disputaron el descubrimiento de la partida de bautismo en Alcalá: Martínez Pingarrón lo manifestó en su correspondencia con Mayans, carta de 12 de agosto de 1752, y Montiano lo hizo público en su Discurso sobre las Tragedias Españolas, como ya se ha señalado.

Durante un cuarto de siglo largo, las personas interesadas por la vida y la obra de Miguel de Cervantes asumieron lo afirmado y publicado por Agustín de Montiano en relación con la participación de Martín Sarmiento, aunque fueron sólo unos pocos los que conocieron que el benedictino se había con- 
formado con hacer correr la voz en los círculos literarios de Madrid a través de su amigo el librero Mena. Y fueron pocos porque el texto Sobre la Zebra, de 1752, en donde el benedictino había dejado plasmado el hallazgo, apenas se divulgó en los círculos cortesanos, como él pretendía en un principio, ya que el conde de Maceda enfermó por aquellas fechas, muriendo en 1754.

Cuando Pellicer i Saforcada publicó en 1778 su Ensayo de una biblioteca de traductores españoles, afirmó que el benedictino había consultado la obra de Diego de Haedo después que tuvo noticias por Juan de Iriarte de la existencia de una relación de 185 cautivos, que expresamente señalaba la circunstancia de que Miguel de Cervantes era natural de Alcalá de Henares. Pellicer basaba sus afirmaciones en una confidencia de Bernardo de Iriarte, después reiterada en una carta, declarando que su tío había encontrado en la biblioteca real una relación antigua de varios cautivos rescatados en Argel, y entre ellos se citaba «con expresión de la edad que entonces tenía, a Miguel de Cervantes Saavedra, natural de Alcalá de Henares» ${ }^{28}$.

Como luego veremos con más detalle, Bernardo de Iriarte daba a entender (y Pellicer asumía) que su tío Juan de Iriarte hizo partícipe de la noticia a Sarmiento para que éste la comprobase y la confirmase. Nosotros creemos, sin embargo, que la razón de que Sarmiento llegase a leer la noticia en la Topographia e Historia General de Argel, y que lo hiciese el año de 1752, no tiene vinculación con Juan de Iriarte ni con la Relación de 185 cautivos, sino con varios hechos coincidentes en la primavera de 1752 .

En primer lugar, tiene que ver con la adquisición del libro de Haedo en esa época, como Sarmiento explica en la Noticia de la verdadera patria de Cervantes: «El año de 1752, entre otros libros, compré el dicho tomo de la Historia de Argel» ${ }^{29}$. Una segunda razón, o coincidencia, para que Sarmiento llegase al texto de Haedo tiene que ver con el trabajo Sobre la Zebra que escribía en aquellas fechas.

En efecto, cuando Sarmiento iniciaba el estudio Sobre la Zebra buceando en los textos antiguos que hablaban del animal, acudió de manera natural al Diccionario de la lengua castellana, publicado por la Real Academia, que en el tomo sexto, de 1739, incorporaba la voz zebra, remitiendo al volumen segundo, de 1729, en donde aparece el vocablo cebra con la cita de un texto de Cervantes. Lo expone bien el benedictino: «El Diccionario de la Real Academia Española, verbo zebra, se remite a la voz cebra; y en su artículo, pone el latín, jumentum silvaticum, y añade un texto castellano de la Historia de D. Quixote, en el capítulo 29 del tomo I. Y es que cuando el cura pensó cabalgar en una mula de alquiler, dice: Haré quenta que voy caballero sobre el caballo Pegaso, sobre la cebra, o alfana, en que cabalgaba aquel famoso moro Muzaraque, que aun hasta ahora yace encantado en la gran cuesta Zulema, que dista poco de la gran Compluto» ${ }^{30}$.

28. Pellicer, Juan A., Ensayo de una biblioteca..., citado, p. 186.

29. Sarmiento, Martín, Noticia de la verdadera patria de el Miguel de Cervantes, citada, $\S 40$.

30. Sarmiento, Martín, Zebra, § 50. 
Conviene recordar que la última parte del párrafo, la que habla de la cuesta de Zulema cercana de la gran Compluto, no aparece en el Diccionario de la Real Academia, aunque sí en el texto del Quijote, como cita Sarmiento, por lo que todo indica que después de leer el texto del Diccionario, el benedictino acudió a la obra de Cervantes para saber qué se decía allí a propósito del moro que cabalgaba en una zebra. Por eso, como hemos puesto en el título de este trabajo, podría decirse que Sarmiento montaba la zebra del moro Muzaraque cuando se encontró con Cervantes en el camino de Alcalá. Coincidió aquello con la adquisición de la obra de Haedo. Y como el mismo Sarmiento señala: «a la primera abertura del libro abrí en la página 185 del Diálogo de los Mártires, en donde está el famoso contexto de que era Cervantes un hidalgo principal de Alcalá de Henares» ${ }^{31}$.

A nuestro modo de ver no fue tan casual que abriera el libro de Haedo por la página 185 , sino que acudió primero al índice final, para comprobar si había en él alguna referencia sobre la zebra ${ }^{32}$. No encontró nada relacionado con el animal, ni en la $\mathrm{C}$ ni en la $\mathrm{Z}$, pero acaso pudo fijarse en esta noticia que aparecía en la tabla final, letra $\mathrm{C}$ : «Vn Cautivo Christiano es muerto a puñaladas en Biserta y porque. 185.2 $»^{33}$. Abrió el libro por esa página y justo allí, en la columna primera, se encontró con la noticia sobre Cervantes. Lo que pasó después, hasta confirmar la noticia con la partida de bautismo, ya lo hemos explicado.

\section{DIFICULTADES PARA VALIDAR LO SEÑALADO POR BERNARDO DE IRIARTE}

Bernardo de Iriarte señalaba en la carta enviada a Juan Antonio Pellicer que al poco tiempo de su llegada a Madrid, procedente de Tenerife tuvo lugar el descubrimiento de su tío Juan. Según el sobrino del bibliotecario Iriarte, los acontecimientos habrían tenido este orden: 1) En 1748 Bernardo se desplaza desde Tenerife a Madrid; 2) En fecha no determinada Juan de Iriarte encuentra y lee en la biblioteca real «una relación antigua de cautivos rescatados por aquellos tiempos en Argel», en donde aparece citado Miguel de Cervantes, como natural de Alcalá de Henares; 3) Al día siguiente, en presencia de su sobrino, Juan de Iriarte da la noticia a Martín Sarmiento, que comienza a hacer diligencias para comprobarlo; 4) Algunas fechas más tarde, sin expresión del tiempo transcurrido, Bernardo de Iriarte se encuentra, con otras personas, en

31. Sarmiento, Martín, Noticia de la verdadera patria de el Miguel de Cervantes, citada, $§ 40$.

32. Que Sarmiento consultase primero los índices de las obras que compraba no tiene nada de particular, sobre todo si tenemos en cuenta que desde 1729 él fue el responsable y autor de los índices del Teatro Crítico y de las Cartas Eruditas de Feijoo.

33. Haedo, Diego de, Topographia e Historia General de Argel, Valladolid: Diego Fernández de Córdoba, 1612, Tabla. No es difícil fijarse precisamente en esa noticia, porque es la única de la letra $\mathrm{C}$ que no comienza con una palabra con $\mathrm{C}$, sino con $\mathrm{V}$ de Vn cautivo... 
la celda de Sarmiento, en donde le oyó decir que había confirmado el descubrimiento de Juan de Iriarte en la obra de Diego de Haedo y «que continuaría las perquisiciones hasta conseguir se sacase en Alcalá la fe de bautismo»; 5) Bernardo leyó la partida de bautismo publicada por Agustín Montiano y la atribución al padre Sarmiento «del descubrimiento que había sido de Juan de Yriarte» y comentó lo publicado por Montiano con su tío «que con su natural moderación no hizo gran caudal del asunto, satisfecho de que se hubiese publicado la noticia» ${ }^{34}$.

En esa secuencia se echa en falta otra noticia esencial, que el tío no habría dejado de señalar al sobrino, y que éste no habría podido olvidar, por su trascendencia. Nos referimos al día en que tuvo la certeza de la existencia de la partida de bautismo en Alcalá antes de que Montiano la publicara, hecho que Juan de Iriarte tuvo que conocer en julio de 1752 porque Martínez Pingarrón la hizo pública en la real biblioteca, como señalamos antes.

Queremos hacer notar, como ya en su día formuló José Luis Pensado, que Bernardo de Iriarte no aportaba en su carta de 20 de agosto de 1772 ningún nombre que pudiese dar verosimilitud y avalar su relato. Sólo hay tres protagonistas: su tío Juan, que ya había muerto un año antes; Sarmiento, muy disminuido psíquica y físicamente, que no leía, no escribía, ni salía ya de su celda de San Martín, en donde fallecerá a las pocas semanas; Bernardo Iriarte, que refiere hechos vividos por un adolescente más dos décadas atrás.

El canario aporta una única fecha: 1748. Es el año de su llegada a Madrid, siendo todavía un niño. Bernardo de Iriarte no dice que fuese entonces cuando tuvo lugar el supuesto descubrimiento de la relación de cautivos por parte de su tío. Tampoco Pellicer hizo esa interpretación en 1778. Pero los lectores de Pellicer acabarán asociando los dos acontecimientos, como hizo, por ejemplo, Fernández de Navarrete en 1819:

El buen éxito de las diligencias de D. Manuel Martínez Pingarrón no se debió tanto a sus propias investigaciones como a las que desde pocos años antes habían practicado D. Juan de Iriarte, docto bibliotecario de SM y el erudito benedictino Fr. Martín Sarmiento, entre quienes debe partirse la gloria de haber sido los descubridores de la verdadera patria de Cervantes (...) Hacia el año de 1748 encontró D. Juan Iriarte en la sala de manuscritos de la biblioteca una relación, impresa en Granada el año de 1581, de 185 cautivos rescatados en Argel el año anterior, entre cuyas partidas se expresaba a Miguel de Cervantes, de edad de 30 años, natural de Alcalá de Henares. Gozoso con este documento, lo manifestó a su sobrino D. Bernardo de Iriarte apenas llegó a su casa, ofreciendo comunicarlo al día siguiente, como lo verificó. Este docto benedictino aplaudió la noticia, y desde luego comenzó a practicar diligencias para comprobarla, como lo consiguió, leyendo la Topografía e Historia de Argel del P. Haedo, coetáneo de Cervantes ${ }^{35}$.

34. Pellicer, Juan A., Ensayo de una biblioteca..., citada, pp. 186-187.

35. Fernández Navarrete, Martín, Vida de Miguel de Cervantes Saavedra, citada, p. 207. Algo parecido afirmaba Leopoldo Rius: «Halló esta partida D. Juan de Iriarte por los años de 1748 á 49, 
Navarrete conoce y cita varios pasajes de la Noticia de la Verdadera Patria de Cervantes así como el párrafo del texto Sobre la Zebra alusivo a Alcalá como patria de Cervantes. Por eso no dejaba de resultarle chocante que Sarmiento se mostrase dubitativo cuatro años después de que supuestamente Iriarte le comunicase la noticia: «ese modo de explicarse [en Sobre la Zebra] parece incompatible con la certeza que se supone tenía».

En principio Navarrete atribuye el descubrimiento a Iriarte y a Sarmiento a partes iguales, porque así lo había señalado Pellicer. Pero tiene serias dudas de que el benedictino lo supiese antes de leerlo en la obra de Haedo. Por eso cita un párrafo de la Obra de 660 Pliegos en el que Sarmiento afirma que nadie había relacionado anteriormente a Cervantes con Alcalá: «Hasta que yo tropecé en la Historia de Argel del P. Haedo con una columna en la cual hay noticia de que Miguel de Cervantes era natural de Alcalá de Henares, se escribía mucho y nada se sabía de la verdadera patria» ${ }^{36}$.

Ya hemos visto que Sarmiento no pudo tropezar con la noticia de Haedo hasta 1752, porque antes de esa fecha no tenía el libro. De modo que, si hacemos caso de sus propias palabras, hasta 1752 nada se sabía de la verdadera patria de Cervantes. Nadie — al menos que supiera Sarmiento - había relacionado a Cervantes con Alcalá entre 1748 y 1752. ¿Mentía Sarmiento en 1766, cuando escribía el párrafo de la Obra de 660 pliegos? ¿Mentía el benedictino en 1761 cuando escribía su Noticia de la verdadera patria de Miguel de Cervantes? ¿Mentía en 1752 en su texto Sobre la Zebra? ¿Mentía en el inventario de sus libros al reseñar las obras que poseía de Cervantes y de Haedo?

Muchas mentiras reiteradas serían esas de alguien como Martín Sarmiento, que de manera desinteresada confía su gran hallazgo al librero Manuel de Mena para que, divulgándolo éste entre sus contertulios y en la biblioteca real, otros pudieran buscar la partida de bautismo. Muchas mentiras serían para alguien que no pretendía la fama relacionada con el nacimiento de Cervantes $^{37}$, porque de ser así amigos no le hubieran faltado que le ayudasen a

en la Biblioteca Real, en una relación impresa en Granada el año de 1581 (...) y comunicó el hallazgo con el P. Sarmiento, quien ya en 1752 conjeturaba que la patria de Cervantes era Alcalá de Henares. Confirmándoselo la presente partida del rescate, llevó adelante sus investigaciones, y gracias á su celo, dos literatos amigos suyos hallaron, casi simultáneamente, la fe de bautismo de Cervantes. Uno de ellos, D. A. Montiano, la publicó en 1752, y el otro, que fue D. Manuel Martínez Pingarrón, la guardó entre sus papeles que, a su fallecimiento, pasaron a manos del señor D. J. A. Pellicer, quien dio a luz la copia en 1778 (Rius, Leopoldo, Bibliografía Crítica de las obras de Miguel de Cervantes Saavedra, II, Madrid: Librería de Murillo, 1899, p. 9).

36. Fernández Navarrete, Martín, Vida de Miguel de Cervantes Saavedra, citada, p. 208.

37. Tampoco pretendió la fama relacionada con Berceo, pues a él se debe la primera edición de las 777 cuartetas de la Vida de Santo Domingo de Silos, aunque lo hizo todo en la sombra y al frente de la edición apareció Sebastián de Vergara, entonces visitador de la congregación benedictina de Valladolid, que no tenía conocimientos ni aficiones históricas, ni literarias, ni lingüísticas. Sarmiento explicó en su Obra de 660 pliegos cómo tuvo lugar: «El año de 1736 quiso el P. Sebastián de Vergara dar a luz la Vida de Santo Domingo de Silos, con la ocasión de que entonces se hizo la Fiesta de la Translación. Disuadíle que formase un tomo de los sermones que se habían predicado, y le persuadí que hiciese venir del archivo de Silos los originales que había de la Vida del Santo, y que se impri- 
encontrar y publicar él mismo la partida. Sobre todo si se tiene en cuenta la influencia que en esas fechas tiene en el entorno del rey, con sus propuestas para los adornos del palacio real ${ }^{38}$. Muchas mentiras hay que atribuir a Martín Sarmiento para que Bernardo de Iriarte ajuste una línea para su tío en la vida de Cervantes. A costa no sólo de la autoridad de Sarmiento en la materia, sino también del prestigio de su tío, a quien Bernardo de Iriarte no deja en buen lugar, seguramente sin pretenderlo.

La poca consistencia que tiene lo señalado por el sobrino de Juan de Iriarte frente a lo declarado por Sarmiento, Martínez Pingarrón y Montiano ya fue evidenciada en su día por José Luis Pensado: Desde 1753, año en que Montiano publicó la partida de bautismo de Cervantes y aclaró que el hallazgo de Sarmiento en el libro de Haedo le había puesto en el camino de Alcalá, tuvo Juan de Iriarte tiempo de reclamar su participación en el hallazgo. Y también tuvo tiempo para explicarlo a sus compañeros de la real biblioteca, y en particular a Martínez Pingarrón, cuando éste hizo pública la partida de bautismo en julio de 1752 .

También hubo muchas ocasiones para que así lo manifestasen su amistades y contertulios, porque, como decía José Luis Pensado: «poco honor se hace a los cenáculos literarios en que D. Juan participaba, si sabiendo que él fue el descubridor de la patria de Cervantes, no tuvo un amigo que reivindicase sus derechos de descubrimiento, y tuvo que esperar a que lo hiciera su sobrino, y precisamente después de su muerte» ${ }^{39}$.

Según su sobrino, Juan de Iriarte tuvo a su alcance la noticia antes que Sarmiento, pero sólo se lo dijo a éste y a su sobrino, ocultándolo a sus compañeros y superiores en la biblioteca. Nada dijo cuando Martínez Pingarrón consiguió la partida de bautismo y la hizo pública en la real biblioteca en julio de 1752. Y nada dijo tampoco cuando Montiano imprimió la fe de bautismo en 1753, porque según explicaba Bernardo, su tío «con su natural moderación no hizo gran caudal del asunto, satisfecho de que se hubiese publicado la noticia». Nosotros creemos que si las cosas hubieran ocurrido como dice el sobrino, tendríamos que tachar a Juan de Iriarte como poco amante de la verdad, poco riguroso, tanto en lo que hace a la investigación científica como a sus tareas de bibliotecario.

miesen. Asintió a eso, vinieron las Actas Latinas de Grimaldo en letra gótica, las 777 cuartetas de Berceo, y los Milagros del Santo, que en el siglo XIII había escrito Don Pedro Marín. Vi esos tres preciosos monumentos y consentí gustoso en que, pasando por mis ojos y manos, y por mi corrección de la imprenta, se imprimiesen con exactitud, en un tomo en $4^{\circ}{ }^{\circ}$, el mismo año de 736» (Sarmiento, Martín, Obra de 660 pliegos. De historia natural y de todo género de erudición, Edición de Henrique Monteagudo, Madrid y Santiago: CSIC-Consello da Cultura Galega, 2008, § 5527).

38. Sarmiento, Martín, Sistema de adornos del Palacio Real de Madrid, Edición de Joaquín Álvarez Barrientos y Concha Herrero, Madrid: Sociedad Estatal de Conmemoraciones Culturales, 2002. Muniain, Sara, El Programa Escultórico del Palacio Real de Madrid y la Ilustración Española, Madrid: Fundación Universitaria Española, 2000.

39. Pensado, José Luis, «Estudio Preliminar» de Noticia de la verdadera patria (Alcalá) de El Miguel de Cervantes, citada, p. 13. 


\section{DUDAS PARA ACEPTAR QUE JUAN DE IRIARTE CONOCIESE LA RELACIÓN IMPRESA POR REBUT}

Pellicer decía haber encontrado casualmente en la biblioteca real una relación impresa en 1581, de 185 cautivos rescatados en Argel por Juan Gil y Antonio de la Bella, entre cuyas partidas pudo leer una relativa a «Miguel de Cervantes, de edad de 30 años, natural de Alcalá de Henares». Aseguraba también que Bernardo de Iriarte le señaló que su tío había descubierto la misma relación en la biblioteca real y que «comunicando la especie de Cervantes con el erudito P. Maestro Sarmiento, acudió éste a la Historia y Topografía de Argel de fr. Diego de Haedo publicada el año de 1612 y con efecto vio confirmada en él la noticia de ser Alcalá la patria del autor de D. Quijote» ${ }^{40}$.

No aporta Pellicer más elementos de la relación impresa por Rebut, aunque suponemos que por lo que hace a Cervantes, y salvando la discrepancia de la edad, se trata de la información contenida en la certificación de la partida del rescate realizado en Argel por fr. Juan Gil en 19 de septiembre de 1580, que Pellicer aporta posteriormente y que trata del rescate de «Miguel de Cervantes, natural de Alcalá de Henares, de edad de 31 años, hijo de Rodrigo de Cervantes y de doña Leonor de Cortinas, vecino de la villa de Madrid, mediano de cuerpo, bien barbado, estropeado del brazo y mano izquierda, cautivo en la galera del sol, yendo de Nápoles a España donde estuvo al servicio de $\mathrm{SM} \gg{ }^{41}$.

Bernardo Iriarte daba a entender (y Pellicer asumía) que Juan de Iriarte hizo partícipe de la noticia a Sarmiento para que éste la comprobase y la confirmase. Cierto es que el libro de Haedo podía ser difícil de encontrar, como se desprende de la correspondencia de Martínez Pingarrón con Mayans. Pero Juan de Iriarte, académico y bibliotecario del rey, encargado entonces de la compra y organización de manuscritos, tenía a su alcance algún ejemplar en la biblioteca real, como lo tuvo Martínez Pingarrón para informar a Mayans. Resulta raro y extraño que Iriarte le pidiera a Sarmiento que confirmara aquel dato en el libro de Haedo cuando lo podía hacer él en la real biblioteca y no podía hacerlo Sarmiento porque no tuvo en su celda la obra de Haedo antes de 1752, por una sencilla razón: La adquirió en 1752 como explicaba en Noticia de la verdadera patria de Miguel de Cervantes.

Creemos que Juan de Iriarte no debió conocer la relación impresa en Granada antes de que Sarmiento señalase en 1752 que Alcalá de Henares era la patria de Cervantes. Porque, si como aseguraba su sobrino, Juan de Iriarte hubiese conocido la relación de cautivos rescatados en Argel por fr. Juan Gil en 1580, no tenía por qué esperar a que Sarmiento confirmase la noticia en Haedo, pues tenía lo principal para emprender el camino hacia la búsqueda de la partida: había que encaminarse hacia Alcalá y buscar en los libros de bautismo en fechas cercanas a 1550 .

40. Pellicer, Juan A., Ensayo de una biblioteca..., citada, pp. 143-144.

41. Ibídem, p. 196. 
Lo que no tiene sentido es que Sarmiento o Juan de Iriarte esperasen a poder confirmarlo en el libro de Haedo. Porque en la relación impresa por Rebut (como en las partidas publicadas por Pellicer y por Vicente de los Ríos) no hay, ni puede haber, noticia que nos lleve a intentar buscar confirmación en la obra de Haedo. La razón es palmaria: la relación y las partidas del rescate son de 1580 y el libro de Haedo, sea obra suya o del doctor Sosa, apareció en 1612. Y tiene poco sentido que Iriarte planteara a Sarmiento la búsqueda en la obra de Haedo partiendo de la relación de cautivos, porque en un texto de 1580 no puede haber noticia referida a un texto de 1612 que a priori se desconoce.

Sí ocurre lo contrario, es decir que a posteriori la obra de Haedo nos puede llevar con cierta facilidad a la partida de bautismo en Alcalá, como hicieron Montiano y Martínez Pingarrón; nos puede llevar a la relación impresa por Rebut, como acaso hicieron Juan de Iriarte y Juan Antonio Pellicer, y también a las partidas del rescate guardadas en el convento de la Trinidad en Madrid, como hicieron Vicente de los Ríos y Juan A. Pellicer ${ }^{42}$. La razón es también palmaria: en la obra de Haedo, y en la página en donde se señala que Cervantes era de Alcalá, aparece noticia que relaciona el rescate con Juan Gil: «Asan Baxa, rey de Argel (...) le pidió mil escudos de oro, en que se rescató, habiendo ayudado en mucho el P. fr. Juan Gil, redentor que entonces era, por la Santísima Trinidad, en Argel» ${ }^{43}$.

Dijimos que Juan de Iriarte no debió conocer la relación de cautivos antes de que Sarmiento diera con la noticia en el libro de Haedo. Y si Iriarte conoció aquel texto, no le sirvió para relacionar a Cervantes y Alcalá. Y es que en diciembre de 1750 apareció en Madrid una nueva edición de la Vida de Cervantes de Mayans, con un particular título: Vida de Miguel de Cervantes Saavedra natural de Madrid. Su editor Alonso Padilla explicaba a Mayans las razones que había tenido para reimprimirla: «la justificación de la patria de Cervantes, es una prueba tan cierta y segura que me alegrara yo poder justificar un derecho en mayorazgo, grande o mediano, con tanta certeza como Vm. prueba el ser Cervantes natural de Madrid. Una tertulia de hijosdalgo naturales de Madrid le damos a Vm. las gracias encarecidamente porque nos ha dado a luz un paisano que estaba escondido en las tinieblas del olvido y con la adicción de ser un autor tan famoso» ${ }^{44}$.

Si cuando salió aquella Vida a finales de 1750, el bibliotecario Iriarte supiese que Cervantes podía ser de Alcalá de Henares y no de Madrid, sin

42. El primero que publicó la partida del rescate de Cervantes fue José Miguel Flores, «Carta escrita sobre la patria de Miguel Cervantes Saavedra», Aduana Crítica, III, 1764, pp. 274-277. Las partidas de rescate de Cervantes (una primera que certifica la entrega a Juan Gil y a Antonio de la Vella de 300 ducados por la madre y la hermana de Cervantes, y una segunda del rescate realizado en Argel por Juan Gil) aparecen en el citado texto de Juan A. Pellicer, Ensayo de una biblioteca... pp. 195-197. El texto de Haedo y las partidas del rescate también las incorporó Vicente de los Ríos, Vida de Miguel de Cervantes y análisis del Quijote, citada, pp. CLXXXII-CLXXXV.

43. Haedo, Diego de, Topographia e Historia General de Argel, citado, fol. 185.

44. Mayans, Gregorio, Epistolario, XII. Mayans y los libreros, edición y estudio de Antonio Mestre, Valencia: Ayuntamiento de Oliva, 1993, p. 34. 
duda que lo habría compartido con sus compañeros de la biblioteca, Nasarre, Santander o Martínez Pingarrón. Y lo habría comentado también con sus contertulios, con sus compañeros de la Real Academia Española, de la que formaba parte, o con alguno de aquellos madrileños hijosdalgo de los que hablaba Pedro J. Alonso Padilla.

Naturalmente, la idea de que Cervantes fuese de Alcalá y no de Madrid suponía un problema económico para Alonso Padilla, y también era un contratiempo para aquellos madrileños de los que hablaba el librero a Mayans, que veían como dejaban de ser paisanos del autor del Quijote. Incluso pudo ser un varapalo para Mayans, en tanto que alguno de sus muchos enemigos aprovechó la ocasión para echarle en cara su poco acierto y crítica, como él mismo señalaba años después a Diego Morales $^{45}$. Pero que Cervantes fuera de Alcalá no era un problema para Juan de Iriarte, por lo que cuesta creer que sabiéndolo no comentase con nadie su descubrimiento, ni siquiera para mostrarse disconforme con el título del libro editado por Alonso Padilla, diciendo que Cervantes acaso no era de Madrid sino de Alcalá.

Igual de incomprensible sería que Juan de Iriarte hubiese descubierto la relación de cautivos después de impresa la Vida de Miguel de Cervantes Saavedra natural de Madrid y no lo hubiera comentado con nadie, excepción hecha de su sobrino adolescente y de Sarmiento. Incomprensible y escasamente riguroso desde el punto de vista científico y poco profesional para un destacado bibliotecario real con más de dos décadas de oficio. En ese sentido, creemos que Bernardo de Iriarte hacía poca justicia a su tío el bibliotecario.

\section{CONJETURA SOBRE LO QUE PUDO PASAR, DEJANDO EN BUEN LUGAR A LOS IRIARTE}

Como ya vimos, Bernardo de Iriarte había llegado a Madrid en 1748. Tenía entonces 13 años. Y cuando se produjo el hallazgo de Sarmiento y el descubrimiento de la partida de bautismo en Alcalá había cumplido 17. Por eso pudo confundir los tiempos y los momentos cuando en 1772 intentaba explicar a Pellicer cómo habían ocurrido los hechos.

No hay duda de que la vía que llevó a Martínez Pingarrón y a Montiano hasta la partida de bautismo en Alcalá pasa por Diego de Haedo y por Martín Sarmiento. Juan de Iriarte no figura en ese camino hasta que lo nombra su sobrino y lo hace público Juan Antonio Pellicer en 1778. Ninguno pudo entonces puntualizar a Pellicer, porque todos los protagonistas - Sarmiento, Juan de Iriarte, Pingarrón y Montiano- ya habían fallecido.

Naturalmente, desde la primavera de 1752 Juan de Iriarte debió tener conocimiento de lo encontrado por Sarmiento, al igual que los bibliotecarios

45. Mayans, Gregorio, Epistolario. XV. Mayans y los altos cargos... 2, Edición y estudio de Antonio Mestre y Pablo Pérez García, Valencia: Ayuntamiento de Oliva, 1997, p. 323. 
Santander y Martínez Pingarrón. Posiblemente, como amigo y contertulio del benedictino, él lo debió conocer por boca de Sarmiento antes que los otros bibliotecarios, a quienes les llegó la noticia a través del librero Manuel de Mena, como explica Sarmiento y como confirma Martínez Pingarrón en su correspondencia con Mayans.

A finales de julio, cuando Martínez Pingarrón hizo pública la fe de bautismo en la real biblioteca, Juan de Iriarte debió conocer la noticia antes que Sarmiento. La confirmación de lo que el benedictino había encontrado en Haedo con el hallazgo y divulgación de la partida de Alcalá por parte de Martínez Pingarrón pudo ser lo que Juan de Iriarte comentó con su sobrino a la vuelta de la real biblioteca y lo que comunicó al día siguiente a Sarmiento.

Nada impide pensar que a partir de entonces Juan de Iriarte hubiese encontrado la relación de los 185 cautivos rescatados y que también lo hubiese comentado a su sobrino. De esa manera quedaría salvada la credibilidad de Bernardo de Iriarte, cuya confidencia a Pellicer pudo verse oscurecida por sus recuerdos juveniles transformados por el tiempo en la mente del adulto Bernardo.

Pusimos en cursiva lo hubiese comentado a su sobrino porque tenemos el convencimiento de que Sarmiento no conoció esa relación, ya que en tal caso lo habría señalado y utilizado de algún modo en alguno de sus escritos posteriores; y particularmente en 1761, cuando el benedictino redactó su Noticia de la verdadera patria (Alcalá) de el Miguel de Cervantes para mostrar que el Miguel de Cervantes bautizado en Alcázar de San Juan en 1558 no podía ser «el verdadero y famoso de Alcalá de Henares (...) estropeado en Lepanto el año de 1571, cautivo en Argel el año 1577, y autor de la inmortal Historia de Don Quijote de la Mancha el año de $1605 »^{46}$.

Recibido: 27 de febrero de 2011

Aceptado: 16 de junio de 2011

46. Sarmiento, Martín, Noticia de la verdadera patria de El Miguel de Cervantes, citada, $\S 129$. 


\title{
Resumen
}

En este estudio se recuerda la importancia que tuvo Martín Sarmiento en el descubrimiento de Alcalá como lugar de nacimiento de Cervantes. Según exponen los autores, la novedad no fue planteada previamente por Juan de Iriarte, como afirmó su sobrino en una carta publicada por Juan Antonio Pellicer, sino únicamente por el benedictino Sarmiento, debido a una triple coincidencia en la primavera de 1752: primero, la redacción del escrito Sobre la Zebra, que llevó a Sarmiento a consultar documentos y textos antiguos, para explicar que las cebras abundaban y se cazaban en la España medieval; segundo, la asociación de la cebra con Cervantes en el Diccionario de la Real Academia; y tercero, la adquisición de la obra de Diego de Haedo en esas mismas fechas. Los autores recuerdan, por otra parte, la inexistencia de datos que avalen que Martínez Pingarrón se anticipó a Agustín Montiano para conseguir la partida de bautismo de Cervantes.

Palabras clave: Historia de la Literatura. Martín Sarmiento. Zebra. Cervantes.

Title: Of what happened when Martin Sarmiento got on the Moor's Muzaraque Zebra and met Cervantes on the road to Alcalá

\begin{abstract}
This study remembers the importance Martín Sarmiento had in the discovery of Cervantes' birthplace. As the authors explain, the novelty was not previously raised by Juan de Iriarte, as it was stated by his nephew in a letter published by Juan Antonio Pellicer. By the contrary, it was Sarmiento who found it in the spring of 1752, due to a triple coincidence: Firstly, the essay of the writing Sobre la Zebra, which drove Sarmiento to look documents and old Spanish texts up, to explain that zebras were hunted in Spain during the Middle Ages; secondly, the association of the word zebra with Cervantes in the Dictionary of the Real Academia Española; and thirdly, the acquisition of Haedo's book on those dates. On the other hand, the authors indicate the nonexistence of information to demonstrate that Martinez Pingarrón got in before Agustin Montiano in obtaining the certificate of Cervantes' baptism.
\end{abstract}

Key words: History of Literature. Martin Sarmiento. Zebra. Cervantes. 